\title{
Importance of the stomach in maintaining calcium homoeostasis in the rat
}

\author{
J Axelson, P Persson, R Gagnemo-Persson, R Håkanson
}

\begin{abstract}
The stomach helps to maintain calcium homoeostasis by making dietary calcium accessible for uptake in the intestines, although the effect of the stomach on calcium homoeostasis is poorly understood. We examined the effect on blood calcium of gastric surgery in the rat. Within three weeks gastrectomy and fundectomy (excision of the acid producing part of the stomach) induced a slight lowering of the blood calcium concentration. When parathyroidectomy was combined with either gastrectomy or fundectomy the blood calcium concentrations promptly dropped to values lower than after parathyroidectomy alone. The mortality was close to $100 \%$ during the first three weeks after combined parathyroidectomy and gastric surgery. It was nil in rats subjected to parathyroidectomy alone. Gastrectomised rats absorbed $\mathrm{Ca}^{2+}$ better than unoperated control rats, possibly reflecting the fact that the serum 1,25-dihydroxyvitamin D concentration was raised. Gastrectomised rats had a food intake that was about $70 \%$ of that in intact rats, and the amount of dietary calcium absorbed (net absorption per $\mathrm{kg}$ body weight) by the gastrectomised rats was approximately $65 \%$ of that in intact control rats. We conclude that the acid producing part of the stomach is important for calcium homoeostasis, since its removal induced lethal hypocalcaemia in parathyroidectomised rats. One possible explanation for the hypocalcaemia induced by gastrectomy is a progressive calcium deficit. In addition, the loss of calciotrophic hormones originating in the stomach may contribute.
\end{abstract}

The stomach is important for the absorption of calcium. Pepsin and acid are thought to act in conjunction to generate soluble calcium from insoluble phosphate complexes in food.' Extensive gastric surgery is known to cause bone disorders (osteomalacia/osteoporosis), possibly

TABLE I The effect of gastric surgery, vagotomy, or parathyroidectomy on the concentration of blood calcium

\begin{tabular}{|c|c|c|c|c|c|}
\hline Operation & $\begin{array}{l}\text { No of } \\
\text { animals }\end{array}$ & $\begin{array}{l}\mathrm{Ca}^{2+} \\
(\mathrm{mmol} / \mathrm{l})\end{array}$ & $p$ & $\begin{array}{l}\mathrm{Ca} a_{\text {tot }} \\
(\mathrm{mmol} / \mathrm{l})\end{array}$ & $p^{\star}$ \\
\hline Sham operation & 14 & $1.33(0.01)$ & - & $2 \cdot 24(0.02)$ & - \\
\hline Vagotomy & 6 & $1.32(0.01)$ & NS & $2 \cdot 24(0.04)$ & NS \\
\hline Antrectomy & 6 & $1.31(0.01)$ & NS & $2.24(0.04)$ & NS \\
\hline Gastrectomy & 8 & $1.29(0.01)$ & $<0.01$ & $2 \cdot 10(0.03)$ & $<0.001$ \\
\hline Fundectomy & 8 & $1.28(0.01)$ & $<0.01$ & $2.05(0.04)$ & $<0.001$ \\
\hline Parathyroidectomy & 28 & $0.96(0.01)$ & $<0.001$ & $1.63(0.04)$ & $<0.001$ \\
\hline
\end{tabular}

Note: Values are expressed as mean (SEM). Blood calcium concentrations were measured in each rat on five occasions over six weeks postoperatively. The mean value for each rat was calculated from the determinations during the six week period. Group means (shown in the table) were calculated from the individual means.

*Value for the difference between sham operated rats and rats subjected to gastric surgery or parathyroidectomy. NS $=$ non signiicant related to an impaired capacity for the utilisation of dietary calcium..$^{2-5}$

In the present study we examined blood calcium concentrations after bilateral truncal vagotomy, which is known to reduce both basal and stimulated acid secretion in the rat by about $90 \%,{ }^{6}$ antrectomy, which reduces basal and stimulated acid secretion in the rat by about $50 \%,{ }^{7}$ fundectomy (excision of the acid producing part of the stomach), or total gastrectomy. Gastric surgery as above was performed before or after parathyroidectomy. We also studied the absorption of orally administered calcium after gastrectomy.

\section{Methods}

ANIMALS

Male Sprague-Dawley rats, weighing about $200 \mathrm{~g}$ at the start of the experiments, were used. They were fed standard rat food pellets (ALAB, Sweden) and tap water unless otherwise stated. The calcium concentration of the food was $12 \mathrm{mg} / \mathrm{g}$ and of the drinking water $62 \mathrm{mg} / \mathrm{l}$.

\section{OPERATIONS}

Surgery was carried out under diethyl ether anaesthesia. Sham operation consisted of a midline abdominal incision and manipulation of the viscera. Parathyroidectomy was achieved by removal of both parathyroid glands by a pair of scissors under a magnifying lens, leaving the rest of the thyroid intact. Bilateral truncal vagotomy was achieved by cutting both vagal trunks immediately below the diaphragm and dissecting the oesophageal wall for additional fibres. A pyloroplasty was made at the same time to prevent food retention. ${ }^{8}$ Antrectomy was performed by removing the distal half of the glandular part of the stomach, including the duodenal bulb, and joining the stomach with the duodenum end-to-end. ${ }^{9}$ Total gastrectomy included removal of the whole stomach followed by oesophagoduodenostomy end-to-end. Fundectomy consisted of removing the acid producing part of the gastric mucosa and joining the rumen and the antrum. ${ }^{10}$ The mortality associated with gastrectomy was $3 \%$ and with fundectomy $10 \%$. During the first week after these two operations there was no gain in body weight. Subsequently the curves showing body weight gain over time for gastrectomised or fundectomised rats were parallel to that for intact rats. The mean (SEM) daily intake of food during the three weeks after operation was $24(1) \mathrm{g}(\mathrm{n}=6)$ in the sham operated rats, $17(1) \mathrm{g}(\mathrm{n}=6)$ in the gastrectomised rats, and 17 (1) $g(n=6)$ in the fundectomised rats. In one series of experiments 
gastrectomised rats and sham operated rats were maintained in individual metabolic cages for three to four days two to three weeks after the operation. This allowed studies of calcium intake and calcium excretion in urine and faeces.

\section{BLOOD SAMPLING}

Unless otherwise stated 50 or $150 \mu$ l samples of blood were drawn from the tip of the tail and collected in heparinised capillary tubes. The tail was anaesthetised with lignocaine (Astra, Sweden).

\section{CALCIUM DETERMINATION}

$\mathrm{Ca}^{2+}$ was determined by a selective electrode (ICA 1, Radiometer, Copenhagen, Denmark) in $150 \mu \mathrm{l}$ samples of fresh whole blood. Total calcium was determined spectrophotometrically in $25 \mu \mathrm{l}$ of serum using a commercially available kit based on the conjugation of calcium with o-cresolphthalein (Calcium C, Wako Chemicals, Neuss, Germany). Ionised and total calcium were determined before each operation and one and three days and one, three, and six weeks after operation.

\section{INTESTINAL ABSORPTION OF IONISED CALCIUM}

Rats were fasted overnight before the start of the experiment. ${ }^{45} \mathrm{CaCl}_{2}$ (specific radioactivity 4-50 Ci/g, NEN-Chemicals, Du Pont, Dreich, Germany) was given orally via a gastric tube. In one experiment ${ }^{45} \mathrm{CaCl}_{2}$ in a dose of $5 \mu \mathrm{Ci} / \mathrm{kg}$ body weight $\left(10^{7} \mathrm{cpm} / \mathrm{kg}\right)$ was given in $1 \mathrm{ml}$ saline and in another $50 \mu \mathrm{Ci} / \mathrm{kg}\left(10^{8} \mathrm{cpm} / \mathrm{kg}\right)$ was added to a suspension of $200 \mathrm{mg}$ food in $2 \mathrm{ml}$ of water. $50 \mu \mathrm{l}$ of blood was drawn 30 minutes and one, two, and three hours after administration of ${ }^{45} \mathrm{CaCl}_{2}$. The blood was added to an aliquot of solubiliser (150 $\mu \mathrm{l}$ Soluene-350/isopropanol, $1: 2$ ). The mixture was incubated for one hour at $40^{\circ} \mathrm{C}$ and decolorised by adding $200 \mu \mathrm{l}$ of $30 \%$ hydrogen peroxide." After two hours at room temperature, $10 \mathrm{ml}$ of Picofluor-40 (Packard) cocktail was added. The vials were capped, vortex mixed, and left standing overnight at room temperature before determination of radioactivity (LKB $\beta$-counter Wallac 1214 Rackbeta).

\section{DETERMINATION OF 25-HYDROXYVITAMIN $\mathrm{D}_{3}$ AND} 1,25-DIHYDROXYVITAMIN D

The serum 25-(OH)-vitamin $\mathrm{D}_{3}$ concentration was determined by a high performance liquid chromatography (HPLC) method. ${ }^{12}$ The method involves passage through Sep-Pak $\mathrm{C}_{18}$ cartridges (Waters, Milford, MA, USA) followed by HPLC in two steps using first a reversed phase column (Nova-Pak $\mathrm{C}_{18}, 4 \mu \mathrm{m} 8 \times 100 \mathrm{~mm}$, Waters) and then a straight phase column (Nova-Pak, $4 \mu \mathrm{m}$ $5 \times 100 \mathrm{~mm}$, Waters). The samples were eluted with methanol/ $\mathrm{H}_{2} \mathrm{O} 70: 30$ ( $\mathrm{vol} / \mathrm{vol}$ ) and hexane/ isopropanol 96:4 (vol/vol), respectively. The method is specific for $25-\mathrm{OH}-\mathrm{D}_{3} \cdot{ }^{12} 1,25(\mathrm{OH})_{2}$ vitamin $\mathrm{D}_{2}$ and $1,25(\mathrm{OH})_{2}$ vitamin $\mathrm{D}_{3}$ in serum were measured by a commercially available
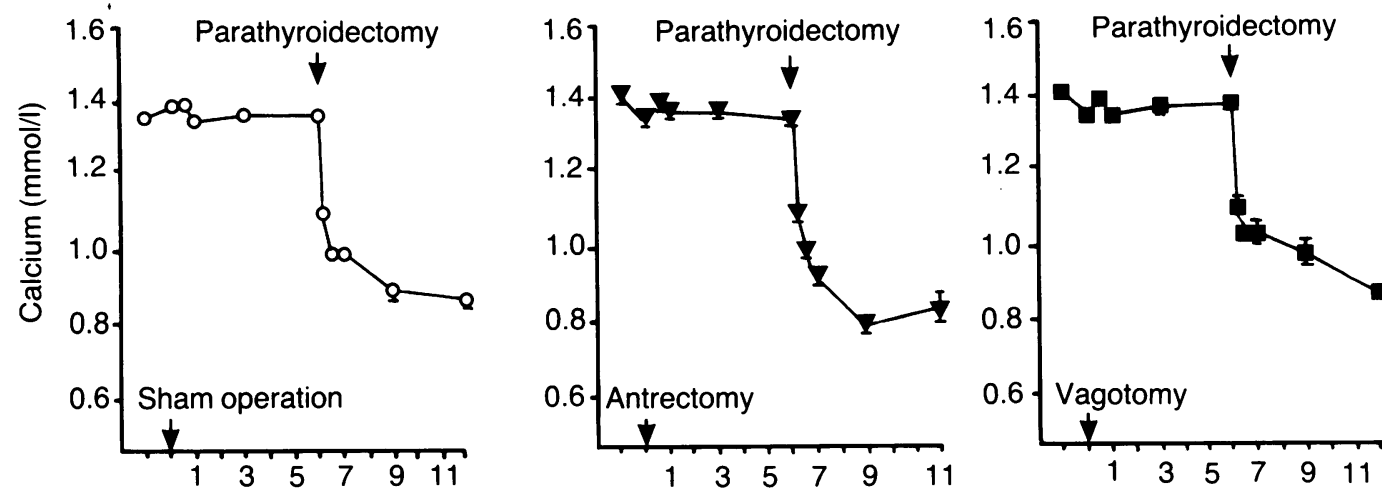

Time (weeks)

Figure 1: Blood $\mathrm{Ca}^{2+}$ concentrations after sham operation, antrectomy, vagotomy, gastrectomy, or fundectomy. Each group comprised seven rats. Six weeks later they all had a parathyroidectomy. After three weeks the mortality was $100 \%$ in the gastrectomy and fundectomy groups and nil in the others.

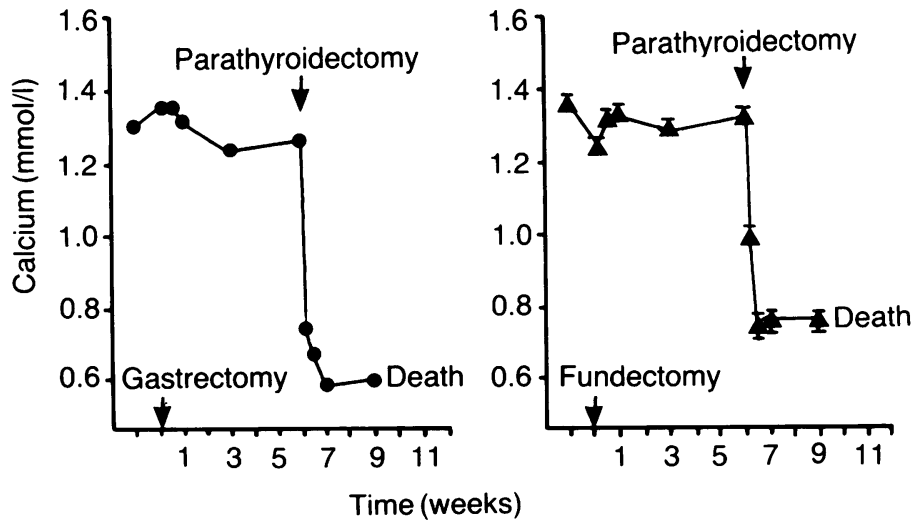




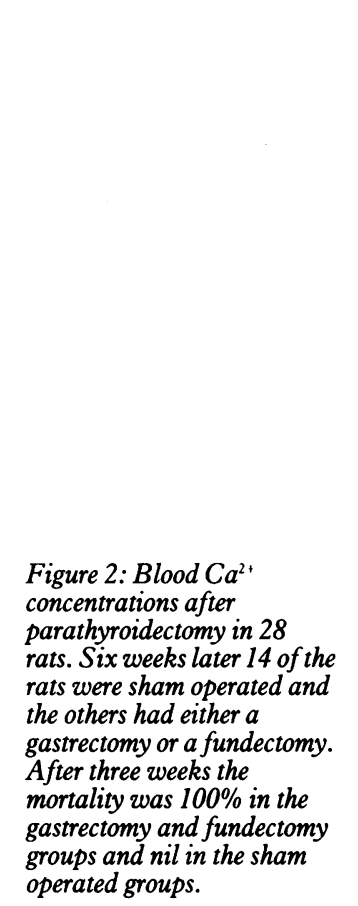

Figure 2: Blood $\mathrm{Ca}^{2+}$ concentrations after pats Siroidectomy in 28 rats were sham operated and the others had either a mortality was $100 \%$ in the groups and nil in the sham After three weeks the operated groups.

\section{O Sham operation Fundectomy}

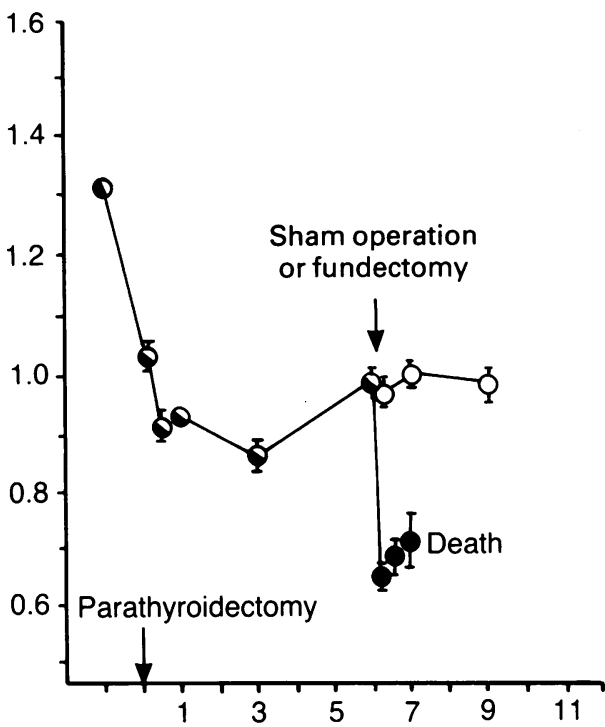

Time (weeks)

radioreceptor assay method (Incstar, Stillwater, $M N$, USA) after passage through a Sep-Pak $\mathrm{C}_{18}$ cartridge. ${ }^{13}$

URINARY AND FAECAL EXCRETION OF CALCIUM Gastrectomised and sham operated rats were maintained in metabolic cages for three to four days. The amount of food and water ingested was measured. The urine and faeces from each rat was collected for each 24 hour period.

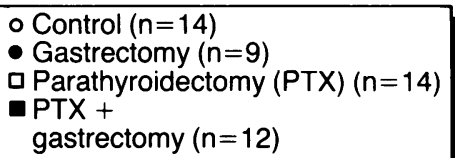

(A)

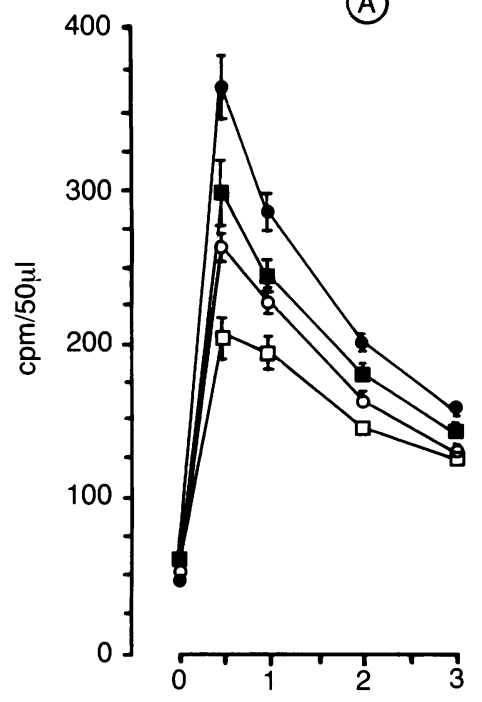

- Control $(n=6)$

- Gastrectomy $(n=7)$

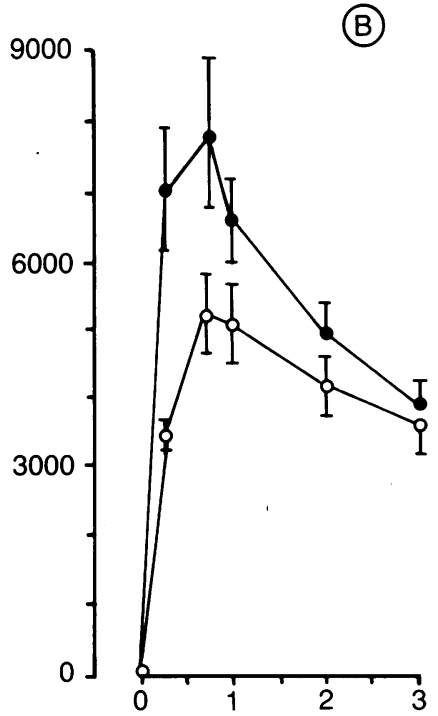

Time (hours)

Figure 3: Uptake of ${ }^{45} \mathrm{Ca}^{2+}$ into blood after oral administration to fasted rats. In $(A)$ the rats received ${ }^{45} \mathrm{CaCl}_{2}$ orally in $1 \mathrm{ml}$ saline; in $(B)$ the rats received 10 times as much ${ }^{45} \mathrm{CaCl}_{2}$ in a suspension of food in $2 \mathrm{ml}$ water. The rats had a sham operation, a gastrectomy or a parathyroidectomy $(P T X)$, or were subjected to combined gastrectomy and parathyroidectomy. ${ }^{45} \mathrm{CaCl}_{2}$ was administered one week after operation and the radioactivity in the blood was followed up.
The volumes and wet weights, respectively, were determined. Faeces were homogenised (Polytron) in $1 \mathrm{~mol} / 1 \mathrm{HCl}(1 \mathrm{~g}$ faeces $/ 10 \mathrm{ml}$ acid $)$ and left standing for three hours at $4^{\circ} \mathrm{C}$ followed by centrifugation at $15000 \times g$ for one hour at $4^{\circ} \mathrm{C}$. The clear supernatant was diluted $1: 50$ with redistilled water. The calcium concentration in urine and faecal extracts was measured by the o-cresolphthalein method and the daily calcium output calculated. With respect to faeces, the mean value for each rat was calculated from the daily determinations during the four day period. Group means were calculated from the individual means.

STATISTICAL ANALYSIS

Student's $t$ test for unpaired values was used. $\mathrm{p}<0.05$ was considered significant. Only groups of four or more rats were included.

\section{Results}

Fundectomy and gastrectomy lowered blood calcium in the rat, while sham operation, vagotomy, or antrectomy were without effect. After parathyroidectomy there was the expected drop in blood calcium (Table I). Determination of ionised calcium and of total blood calcium showed much the same changes. Parathyroidectomy promptly lowered blood calcium also when performed after gastric surgery. In fact, the drop evoked by parathyroidectomy was more pronounced in the gastrectomised and fundectomised rats than in the sham operated, antrectomised, or vagotomised rats (Fig 1). After parathyroidectomy the mortality in the latter three groups was nil, while it was $100 \%$ in the gastrectomised or fundectomised rats. Total blood calcium changed in parallel with the changes in ionised calcium (data not shown).

In another series of experiments the order of the operations was reversed so that parathyroidectomy was followed by gastrectomy or 
TABLE II Concentrations of forms of vitamin $D$ in the serum

\begin{tabular}{lll}
\hline & $\begin{array}{l}\text { 25-hydroxyvitamin } D_{3} \\
(\mu \mathrm{g} / \mathrm{l})\end{array}$ & $\begin{array}{l}\text { 1,25-hydroxvitamin } D \\
(\text { ng/l) }\end{array}$ \\
\hline Sham operation & $33(3)(27)$ & $97(2)(8)$ \\
Gastrectomy & $16(1)^{\star}(13)$ & $136(5)^{\star}(8)$ \\
\hline
\end{tabular}

Mean (SEM). Number of rats in parenthesis. Gastrectomised rats were killed three weeks after the operation.

${ }^{\star} \mathrm{p}<0 \cdot 001$.

fundectomy. In these rats the gastric surgery induced a dramatic drop in the blood calcium concentration, which was already low because of the parathyroidectomy (Fig 2). Also, these animals died during the subsequent postoperative period, while those that had a parathyroidectomy and were sham operated survived. The changes in total blood calcium followed those in ionised calcium (data not shown).

In a third series of experiments rats were subjected to gastrectomy or sham operation. A week later they were fasted for 48 hours and given ${ }^{45} \mathrm{CaCl}_{2}$ by the oral route. Half of the rats received ${ }^{45} \mathrm{CaCl}_{2}$ in saline, the other half received it in a food suspension. The uptake of radioactivity in the circulation was monitored. The results, which are shown in Fig 3, suggested an enhanced capacity of the intestines to absorb $\mathrm{Ca}^{2+}$ after gastrectomy. Parathyroidectomy reduced the absorption of $\mathrm{Ca}^{2+}$ both in gastrectomised and intact rat. Determination of 25hydroxyvitamin $\mathrm{D}_{3}$ and 1,25-hydroxyvitamin $\mathrm{D}$ in the serum of gastrectomised and sham operated rats showed a reduction in the 25hydroxyvitamin $\mathrm{D}_{3}$. concentration and a rise in the 1,25-dihydroxyvitamin $\mathrm{D}$ concentration three weeks after gastrectomy (Table II).

Finally, the daily intake and urinary and faecal excretion of calcium in five gastrectomised and five sham operated rats in metabolic cages were followed over three to four days two to three weeks after surgery. The gastrectomised rats weighed $258(14) \mathrm{g}$ and the sham operated rats 320 (8) g. The daily intake of water was approximately $20 \mathrm{ml} /$ day in the two groups. The daily food intake was lower in the gastrectomised rats than in the sham operated rats: $12(2) \mathrm{g} v 18$ (1) g. Thus the mean daily intake of calcium was $145 \mathrm{mg}$ (144 mg in food and $1 \mathrm{mg}$ in water) gastrectomised rats and $217 \mathrm{mg}$ ( $216 \mathrm{mg}$ in food and $1 \mathrm{mg}$ in water) in sham operated rats. Expressed per kg body weight, the intake was $562 \mathrm{mg} / \mathrm{kg}$ in the gastrectomised rats and $678 \mathrm{mg} / \mathrm{kg}$ in the sham operated rats. The daily faecal calcium output was lower in the gastrectomised rats than in the sham operated rats: $77(8) \mathrm{mg} v 90(7) \mathrm{mg}$. Thus the amount of calcium absorbed in the gastrectomised rats was calculated to $68 \mathrm{mg}$ ( $47 \%$ of the ingested calcium) while the corresponding value for the controls

TABLE III Daily urinary calcium output in gastrectomised and sham operated rats

\begin{tabular}{|c|c|c|c|c|c|c|}
\hline \multirow[b]{2}{*}{ Operation } & \multicolumn{2}{|l|}{ Day I } & \multicolumn{2}{|l|}{ Day 2} & \multicolumn{2}{|l|}{ Day 3} \\
\hline & $\begin{array}{l}\text { Urine } \\
\text { volume }(m l)\end{array}$ & $\begin{array}{l}\text { Calcium } \\
\text { output (mg) }\end{array}$ & $\begin{array}{l}\text { Urine } \\
\text { volume }(m l)\end{array}$ & $\begin{array}{l}\text { Calcium } \\
\text { output (mg) }\end{array}$ & $\begin{array}{l}\text { Urine } \\
\text { volume }(m l)\end{array}$ & $\begin{array}{l}\text { Calcium } \\
\text { output (mg) }\end{array}$ \\
\hline $\begin{array}{l}\text { Gastrectomy (13) } \\
\text { Sham operation (16) }\end{array}$ & $\begin{array}{r}5 \cdot 0(1 \cdot 0) \\
11 \cdot 0(2 \cdot 0)\end{array}$ & $\begin{array}{l}0.28(0.02) \\
1.44(0.18)\end{array}$ & $\begin{array}{r}7 \cdot 0(3 \cdot 0) \\
13 \cdot 0(2 \cdot 0)\end{array}$ & $\begin{array}{l}0.30(0.03) \\
1.49(0.24)\end{array}$ & $\begin{array}{r}6 \cdot 0(1 \cdot 0) \\
12 \cdot 0(2 \cdot 0)\end{array}$ & $\begin{array}{l}0.27(0.03) \\
1.67(0.17)\end{array}$ \\
\hline
\end{tabular}

Mean (SEM). Number of rats in parenthesis.

The rats were placed in metabolic cages three weeks after surgery. was $127 \mathrm{mg}$ ( $59 \%$ of the ingested calcium). Expressed per $\mathrm{kg}$ body weight, the amount of calcium absorbed was $264 \mathrm{mg} / \mathrm{kg}$ in the gastrectomised rats and $397 \mathrm{mg} / \mathrm{kg}$ in the sham operated rats. Thus the gastrectomised rats absorbed $65 \%$ of the amount of calcium absorbed by the sham operated rats. The urine volumes of the gastrectomised rats were lower than in the sham operated rats and the daily urinary calcium output was reduced to about a fifth (Table III).

\section{Discussion}

Neither vagotomy nor antrectomy affected the blood calcium concentration while gastrectomy and fundectomy induced a slight reduction. The combination of gastrectomy or fundectomy with parathyroidectomy resulted in very low blood calcium concentrations, lower than those seen after parathyroidectomy alone. Unlike parathyroidectomised rats, these rats did not survive more than three weeks, possibly because of the hypocalcaemia. The results indicate that the stomach is important for maintaining calcium homoeostasis. A calcium deficit after gastrectomy may reflect an impaired capacity to convert insoluble dietary calcium into soluble calcium salts that can be absorbed in the small intestine. This suggests an important role for the acid secretory capacity of the stomach. Indeed, the amount of calcium (per $\mathrm{kg}$ body weight) absorbed by the gastrectomised rats was only about $65 \%$ of that absorbed by the sham operated controls. The question is whether a $35 \%$ reduction in the amount of calcium absorbed can explain the effects of gastrectomy on calcium homoeostasis. We obtained no evidence that gastrectomy impairs the capacity of the upper small intestine to absorb $\mathrm{Ca}^{2+}$. In fact, gastrectomised rats were found to absorb $\mathrm{Ca}^{2+}$ better than intact rats, which may be due to the high serum concentration of 1,25-dihydroxyvitamin $\mathrm{D}$ (see also ${ }^{14}$ ). Parathyroidectomy reduced the capacity to absorb $\mathrm{Ca}^{2+}$. This probably reflects an impairment of the vitamin $D$ regulated calcium absorption, as the parathyroid hormone stimulates the formation of bioactive dihydroxylated vitamin D. ${ }^{15}$ Analogous to this, the enhanced capacity to absorb $\mathrm{Ca}^{2+}$ after gastrectomy may reflect an activated vitamin D dependent absorption.

Interestingly, gastrectomised rats excreted much less calcium in the urine and had smaller urine volumes than sham operated rats. During the observation period the water intake did not differ between the two groups. We have no explanation for what seems to be a calcium sparing effect of gastrectomy. It may merely reflect the reduced blood calcium.

Gastrectomy in humans is associated with hypocalcaemia and reduced bone mineral

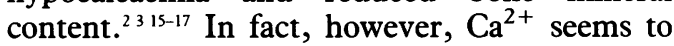
be absorbed more effectively in gastrectomised patients than in normal subjects. ${ }^{18}$ The serum vitamin $\mathrm{D}$ concentrations are raised in such patients, ${ }^{418}$ which may explain the consequent enhancement of the ability of the small intestine to absorb calcium. ${ }^{18}$ Achlorhydria is thought to be associated with impaired utilisation of dietary calcium in humans. ${ }^{1920}$ The results of the present 
study provide some support for this view but the role of gastric acid in calcium absorption is still far from clear. ${ }^{2}$

The stomach may play an important part in calcium homoeostasis apart from that of producing acid to promote the utilisation of dietary calcium. Recently it was suggested that the acid producing mucosa harbours a calciotrophic agent, gastrocalcin, which is released in response to gastrin and food intake. ${ }^{22-24}$ Gastrocalcin seems to stimulate the uptake of calcium into bone and to cause hypocalcaemia as a consequence. The effects of gastrocalcin deficiency and its contribution to the effects of gastrectomy remain to be identified. At present there is no explanation for the apparent paradox that the stomach is thought to produce a hypocalcaemic hormone while gastrectomy causes hypocalcaemia. This study was supported by grants from the Swedish MRC (04X1007), the Tercentenary Foundation of the
the Stohnes Foundation, and AB Hässle.

1 Sheikh MS, Santa Ana CA, Nicar MJ, Schiller LR, Fordtran JS. Gastrointestinal absorption of calcium from milk and
calcium salts. $N E n g l 7$ Med 1987; 317:532-6.

2 Blichert-Toft M, Beck A, Christiansen C, Transböl I. Effects of gastric resection and vagotomy on blood and bone mineral content. World F Surg 1979; 3: 99-102.

3 Imawari M, Kozawa K, Akanuma Y, Koizumi S, Itakura H, Kosaka K. Serum 25-hydroxyvitamin D and vitamin Dbinding protein levels and mineral metabolism after partia and total gastrectomy. Gastroenterology 1980; 79: 255-8.

4 Nilas L, Christiansen C, Christiansen J. Regulation of vitamin $\mathrm{D}$ and calcium metabolism after gastrectomy. Gut 1985; 26: 252-7.

5 Koga S, Nishimura O, Iwai N, Kishi K, Takeuchi T, Hinohara T, Okamoto T. Clinical evaluation of long-term

6 Håkanson R, Hedenbro J, Liedberg G, Vallgren S. Effect of vagotomy on gastric acid secretion in the rat. Acta Physiol Scand 1982; 115: 135-9.

7 Lundell L. Alterations in secretory patterns following antrectomy in rats with Pavlov pouches. $\mathscr{f} P$ hysiol $1975 ; 245$ 737-54.
- 8 Shay H, Komarov SA, Gruenstein M. Effects of vagotomy in the rat. Arch Surg 1949; 59: 210-3.

9 Håkanson R, Larsson L-I, Liedberg G, Oscarson J, Sundler $F$, Vang J. Effects of antrectomy or porta-caval shunt on the $F$, Vang J. Effects of antrectomy or porta-caval shunt on the histamine-storing endocrine like cells in the oxy

10 Oscarson J, Håkanson R, Liedberg G, Lundqvist G, Sundler GF, Thorell J. Variated serum gastrin concentration: Trophic effects on the gastrointestinal tract. Acta Physiol Scand 1979; suppl 475: 1-27.

11 Moore PA. Preparation of whole blood for liquid scintillation counting. Clin Chem 1981; 27: 609-11.

12 Lindbäck B, Berlin T, Björkhem I. Three commercial kits and one liquid-chromatographic method evaluated for determining 25-hydroxyvitamin $\mathrm{D}_{3}$ in serum. Clin Chem 1987; 33 $1226-7$

3 Hollis BW. Assay of circulating 1,25-dihydroxyvitamin D involving a novel single-cartridge extraction and purification procedure. Clin Chem 1986; 32:2060-3.

14 Shoen MS, Lindenbaum J, Roginsky MS, Holt PR. Significance of serum levels of 25-hydroxycholecalciferol in gastrointestinal disease. Am F Dig Dis 1978; 23: 137-42.

15 Rasmussen $\mathrm{H}$, Wong M, Bikle D, Goodman DBP. Hormonal control of the renal conversion of 25-hydroxycholecalciferol to 1,25-dihydroxycholecalciferol. F Clin Invest 1972; 51: 2502-4.

16 Morgan DB, Paterson CR, Woods CG, Pulvertaft CN, Fourman P. Osteomalacia after gastrectomy - a response to very small doses of vitamin D. Lancet 1965; ii: 1089-91.

17 Aukee S, Alhava EM, Karjalainen P. Bone mineral after partial gastrectomy II. Scand $\mathcal{F}$ Gastroenterol 1975; 10: $165-9$

18 Agnew JE, Holdsworth CD. The effect of fat on calcium absorption from a mixed meal in normal subjects, patients
with malabsorptive disease, and patients with a partial with malabsorptive disease, and patients with
gastrectomy for gastric cancer. Gut 1967; 8: 260-6.

19 Recker R. Calcium absorption and achlorhydria. $N$ Engl $\mathcal{F}$ Med 1985; 313: 70-3.

20 Eastell R, Calcium absorption and achlorhydria (letter). NEngl F Med 1985; 313: 1481-2.

21 Bo-Linn GW, Davis GR, Buddrus DJ, Morawski SS, Santa Ana C, Fordtran JS. An evaluation of the importance of gastric acid secretion in the absorption of dietary calcium ҰClin Invest 1984; 73: 640-7.

22 Persson $\mathrm{P}$, Håkanson $\mathrm{R}$, Axelson $\mathrm{J}$, Sundler F, Gastrin releases a blood calcium-lowering peptide from the acidreleases a blood calcium-lowering peptide from the acidproducing part of

23 Håkanson R, Persson P, Axelson J, Johnell O, Sundler F. Evidence that gastrin stimulates ${ }^{45} \mathrm{Ca}$ uptake into bone through release of a gastric hormone. Regul Pept 1990; 28: 107-18.

24 Håkanson R, Persson P, Axelson J. Elevated serum gastrin after food intake or acid blockade evokes hypocalcemia. Regul Pept 1990; 28: 131-6. 